\title{
Orexin Neurons Respond Differentially to Auditory Cues Associated with Appetitive versus Aversive Outcomes
}

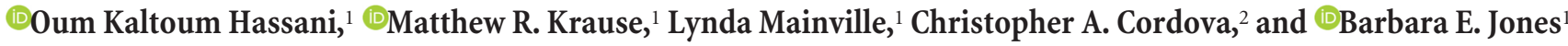 \\ ${ }^{1}$ Department of Neurology and Neurosurgery, Montreal Neurological Institute, McGill University, Montreal, Quebec, Canada H3A 2B4, and ${ }^{2}$ Division of \\ BioMedical Sciences, Memorial University, St. John's, Newfoundland, Canada A1B 3X9
}

Orexin (Orx) neurons are known to be involved in the promotion and maintenance of waking because they discharge in association with cortical activation and muscle tone during waking and because, in their absence, waking with muscle tone cannot be maintained and narcolepsy with cataplexy ensues. Whether Orx neurons discharge during waking in association with particular conditions, notably with appetitive versus aversive stimuli or positive versus negative emotions, is debated and considered important in understanding their role in supporting particular waking behaviors. Here, we used the technique of juxtacellular recording and labeling in head-fixed rats to characterize the discharge of Orx neurons during the performance of an associative discrimination task with auditory cues for appetitive versus aversive outcomes. Of 57 active, recorded, and neurobiotin-labeled neurons in the lateral hypothalamus, 11 were immunohistochemically identified as Orx-positive $\left(\mathrm{Orx}^{+}\right)$, whereas none were identified as melanin-concentrating hormone-positive. Orx ${ }^{+}$neurons discharged at significantly higher rates during the tone associated with sucrose than during the tone associated with quinine delivered upon licking. They also discharged at high rates after the tone associated with sucrose. Across periods and outcomes, their discharge was positively correlated with EEG gamma activity and EMG activity, which is indicative of cortical activation and behavioral arousal. These results suggest that Orx neurons discharge in a manner characteristic of reward neurons yet also characteristic of arousal neurons. Accordingly, the Orx neurons may respond to and participate in reward processes while modulating cortical activity and muscle tone to promote and maintain arousal along with learned adaptive behavioral responses.

Key words: arousal; EEG; EMG; MCH; reward; sleep

Significance Statement

Orexin neurons play a critical role in promoting and maintaining a waking state because, in their absence, narcolepsy with cataplexy ensues. Known to discharge during waking and not during sleep, they have also been proposed to be selectively active during appetitive behaviors. Here, we recorded and labeled neurons in rats to determine the discharge of immunohistochemically identified orexin neurons during performance of an associative discrimination task. Orexin neurons responded differentially to auditory cues associated with appetitive sucrose versus aversive quinine, indicating that they behave like reward neurons. However, correlated discharge with cortical and muscle activity indicates that they also behave like arousal neurons and can thus promote cortical activation with behavioral arousal and muscle tone during adaptive waking behaviors.

\section{Introduction}

Orexin (Orx or hypocretin) is a highly important neuropeptide in the brain, in absence of which waking with muscle tone cannot be maintained and narcolepsy with cataplexy occurs (Peyron et al.,

Received Oct. 28, 2015; revised Dec. 22, 2015; accepted Dec. 24, 2015.

Author contributions: 0.K.H., C.A.C., and B.E.J. designed research; 0.K.H. and L.M. performed research; 0.K.H., M.R.K., and B.E.J. analyzed data; 0.K.H. and B.E.J. wrote the paper.

This work was supported by Canadian Institutes of Health Research (CIHR Grant MOP-82762 to B.E.J.) and the National Institutes of Health (Grant R01 MH-60119-01A to B.E.J.). C.A.C. was supported by a postdoctoral fellowship from the National Science Foundation (NSF) in the laboratory of B.E.J. at the Montreal Neurological Institute. M.R.K. was paid from a grant by Le Ministre du Développement Économique de l'Innovation et de l'Exportation (MDEIE Grant PSR-SIIRI-729) awarded to Christopher C. Pack at the Montreal Neurological Institute. We thank Jocelyn Roy, Nuha Jabakhanji and Faisal Naqib for assistance in data acquisition and processing.
2000; Thannickal et al., 2000; Nishino and Mignot, 2011). Its role in maintaining waking has been demonstrated experimentally by the generation of narcolepsy-cataplexy in knock-out mice with genetic deletion of pre-pro Orx (Chemelli et al., 1999) and by pharmacological reduction of waking with cortical activation and muscle tone using Orx receptor antagonists (Black et al., 2013). Moreover, Orx neurons have been shown to promote awakening from sleep by optogenetic stimulation in mice (Adamantidis et

The authors declare no competing financial interests.

Correspondence should be addressed to Barbara E. Jones, Montreal Neurological Institute, 3801 University Street, Montreal, QC, Canada H3A 2B4. E-mail: barbara.jones@mcgill.ca.

D0I:10.1523/JNEUROSCI.3903-15.2016

Copyright $\odot 2016$ the authors $\quad 0270-6474 / 16 / 361747-11 \$ 15.00 / 0$ 
al., 2007). From in vitro electrophysiological studies, it is known that Orx excites neurons of all of the major arousal systems and can thus play a central role in promoting arousal (for review, see Jones and Muhlethaler, 2005; Tsujino and Sakurai, 2009). From in vivo recording studies, it is also known that Orx neurons discharge during waking and cease firing during sleep, including REM (or paradoxical) sleep with muscle atonia, and that their discharge is positively correlated with gamma EEG and EMG activity across the sleep-wake cycle of rats (Lee et al., 2005). However, it was also suggested from single-unit recording studies that Orx neurons might fire in association with particular stimuli and behaviors during waking (Mileykovskiy et al., 2005).

In fact, it has been proposed that Orx neurons in the lateral hypothalamus (LH) play a selective role in promoting food intake, along with drug seeking and thus reward processes (Harris et al., 2005). Evidence that Orx neurons in the LH would be active during these behaviors was based upon c-Fos expression during anticipation of rewards and absence thereof after exposure to novel or aversive stimuli in rats (Harris et al., 2005). However, even though c-Fos protein may reflect enhanced levels of neural activity, it does not serve as an indicator of the presence or absence of neural discharge because it depends upon the pattern of firing and receptor activation (Luckman et al., 1994; Fields et al., 1997; Guo et al., 2007). Clearly, the activity of Orx neurons in association with appetitive versus aversive outcomes can only be determined by electrophysiological recording of identified Orx neurons.

In the present study, we sought to record Orx neurons in head-fixed rats performing a task to discriminate auditory cues associated with sucrose versus quinine or in a second procedure, with sucrose versus no sucrose outcomes. The recorded neurons were labeled using the juxtacellular technique with neurobiotin $\mathrm{Nb})$ for subsequent immunohistochemical staining for Orx. The sections were also stained for melanin-concentrating hormone $(\mathrm{MCH})$, which is contained in codistributed neurons that have also been implicated in reward processes (Georgescu et al., 2005). We were thus able to determine, in the lateral hypothalamus, the discharge of chemically identified neurons during response to conditioned stimuli associated with appetitive versus aversive outcomes.

\section{Materials and Methods}

Animals and surgery. All procedures used in this study were approved by the McGill University Animal Care Committee and the Canadian Council on Animal Care. A total of 91 adult male Long-Evans rats (200-250 g or $\sim 47-55 \mathrm{~d}$ at the beginning of the experiment; Charles River Laboratories) housed under a 12:12 h light/dark schedule with lights on from 7:00 A.M. to 7:00 P.M. were used. Animals were operated under deep anesthesia (ketamine, xylazine, and acepromazine: $65 / 5 / 1 \mathrm{mg} / \mathrm{kg}$ in a mixture of $2 \mathrm{ml} / \mathrm{kg}$ initial dose and $1 \mathrm{mg} / \mathrm{kg}$ booster as needed, i.p.) for implantation of a metal u-frame and chronically indwelling electrodes for recording EEG (epidural screws over anterior medial prefrontal and retrosplenial cortices) and for recording EMG (silver wire loops in the neck muscles) (Lee et al., 2004). After recovery for $\sim 2 \mathrm{~d}$ after surgery, animals were introduced to the head fixation apparatus for habituation during a period of $\sim 1$ week. The metal $\mathrm{u}$-frame, which was subsequently attached during recording by screws to a sliding carriage adapter within the stereotaxic frame, was positioned such that it allowed subsequent opening of the skull and stereotaxic descent of glass micropipettes to the deep target in the brain (Soulière et al., 2000). In this manner, even in naturally waking/sleeping rats, the head was securely fixed for juxtacellular recording with glass micropipettes (Lee et al., 2004).

Associative discrimination task. To optimize rats' motivation to work in the behavioral task, animals were mildly food deprived to $95 \%$ of their free-feeding weight and limited in the time that they had access to water to $3 \mathrm{~h} / \mathrm{d}$ (3:00-6:00 P.M.) during training and experimentation, which was done on weekdays. Rats were trained to respond to distinctive auditory cues presented during a $2 \mathrm{~s} \mathrm{time} \mathrm{window} \mathrm{at} \mathrm{either} \mathrm{a} \mathrm{minimally} \mathrm{high} \mathrm{frequency}(4.5$ $\mathrm{kHz}$, Tone 1$)$ or a lower frequency $(0.9 \mathrm{kHz}$, Tone 2$)$ and at a moderate intensity ( $\sim 60 \mathrm{~dB}$ at their heads). These tones both fall within a relatively low range of frequencies within which rats of $<5$ months of age (as used here, ranging between 2.5 and 4.5 months during training and testing) show a similar sensitivity and to which the rats would not be expected to respond differently when the tones are delivered in a suprathreshold range as used here (Cowles and Pennington, 1943; Dube et al., 1993; Heffner et al., 1994). The tones were followed by drops of liquid delivered through different tubes situated in front of the rat's mouth when the rat responded by licking (to break an infrared beam) within a $6 \mathrm{~s}$ time window after the end of tone presentation. To foster the rats' motivation to respond to the task, a bigger drop was delivered if rats responded within the first $2 \mathrm{~s}$ after the end of tone presentation. The animal's performance was tested on a daily basis using increasing blocks of randomly alternating Tone 1 and Tone 2 trials with a duration of $24 \pm 2$ s per trial. Latency and percentage of licking response and the number of licks were measured and analyzed for comparison (using paired $t$ tests) on a daily basis during training. This was continued until a significant difference was established in the animal's response to Tone 1 and Tone 2 for 3 consecutive days as evidence of its learning.

Two different procedures were used in different groups of rats. In the first procedure using sucrose versus quinine (S/Q), rats were trained such that they could respond after the presentation of Tone 1 to receive a drop of an appetitive sucrose (15\%) solution and not respond after presentation of Tone 2 to avoid a drop of an aversive, moderately bitter quinine (0.015-0.03 M) solution with partial reinforcement for both sucrose and quinine (of 75\%). With the S/Q procedure, up to 6 weeks of training were necessary for the animals to learn to discriminate between Tone 1 and Tone 2 and thus reach learning criteria in the presence of the aversive quinine solution. In a second procedure using sucrose versus nonsucrose (S/NS), which was aimed at facilitating and accelerating the animal's learning process, rats were trained such that response to Tone 1 was reinforced $100 \%$ of the time with sucrose and Tone 2 with no sucrose. With the S/NS procedure, only 3 weeks of training were necessary for the rats to learn to discriminate between Tone 1 and Tone 2 and reach learning criteria. During testing and recording, the reinforcement was omitted by the experimenter in a number of trials to facilitate unit recording and also to test whether the consumption of sucrose or quinine affected the behavioral and unit response.

Juxtacellular recording and labeling. After reaching learning criteria, rats were once again anesthetized and operated for drilling holes in the skull (AP $-2.8 \mathrm{~mm}$ from bregma, $\mathrm{L} \pm 1.3 \mathrm{~mm}$ from midline) and opening the dura over the lateral hypothalamus on each side. After $1 \mathrm{~d}$ of recovery, daily recording sessions of $\sim 4$ h (between $\sim 11: 00$ A.M. and 17:00 P.M.) were performed on animals during testing under the $\mathrm{S} / \mathrm{Q}$ in one group or S/NS procedure in another group of rats. Single units were recorded using glass micropipettes ( $\sim 1 \mu \mathrm{m}$ tip) filled with $0.5 \mathrm{M} \mathrm{NaCl}$ and $\sim 5 \% \mathrm{Nb}$ (Vector Laboratories) and an intracellular amplifier (Neurodata IR-283A; Cygnus Technology). The unit signal was amplified $(2000 \times)$ and filtered $(0.3-3 \mathrm{kHz})$ using a CyberAmp380 (Molecular Devices) and then acquired at $30 \mathrm{kHz}$ for online viewing with Axoscope (version 8.1; Molecular Devices). The unit activity with EEG/EMG activity (digitized at $30 \mathrm{kHz}$ ), behavioral events (Tone 1, Tone 2, sucrose delivery, quinine delivery, and licking), along with video images, were recorded simultaneously on customized digital data acquisition systems using Cheetah version 5 software from Neuralynx. After successful recording of a unit during behavioral testing (for at least one trial per tone), the cell was submitted to the juxtacellular labeling procedure (Pinault, 1996; Lee et al., 2004).

Histochemistry. After juxtacellular labeling of not more than one neuron per side, the rat was anesthetized with an overdose of sodium pentobarbital (Euthanyl, $\sim 100 \mathrm{mg} / \mathrm{kg}$, i.p.) and perfused with a $4 \%$ paraformaldehyde solution. Brains were immersed in $30 \%$ sucrose for $2-3 \mathrm{~d}$ and then frozen for storage and subsequent cutting into $25-\mu \mathrm{m}-$ thick sections. To reveal $\mathrm{Nb}$, sections were incubated for $2.5 \mathrm{~h}$ in Cy2-conjugated streptavidin (1:1000; Jackson ImmunoResearch Laboratories). Once the Nb-labeled cell was located, the relevant section 


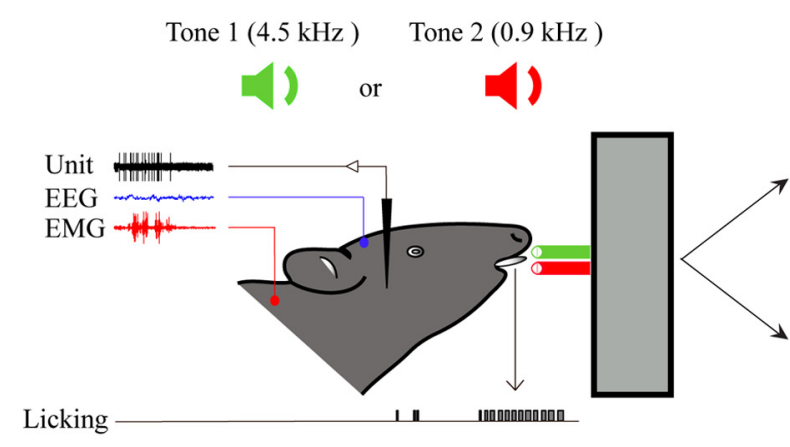

Sucrose delivery in $75 \%$ of trials associated with Tone 1

Licking

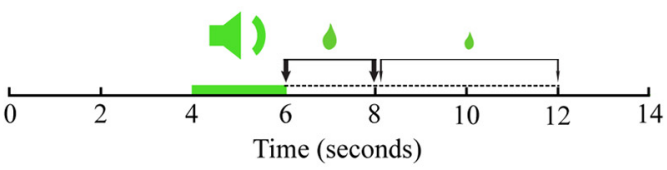

Quinine delivery in 75\% of trials associated with Tone 2

B

$\mathrm{S} / \mathrm{NS}$ procedure

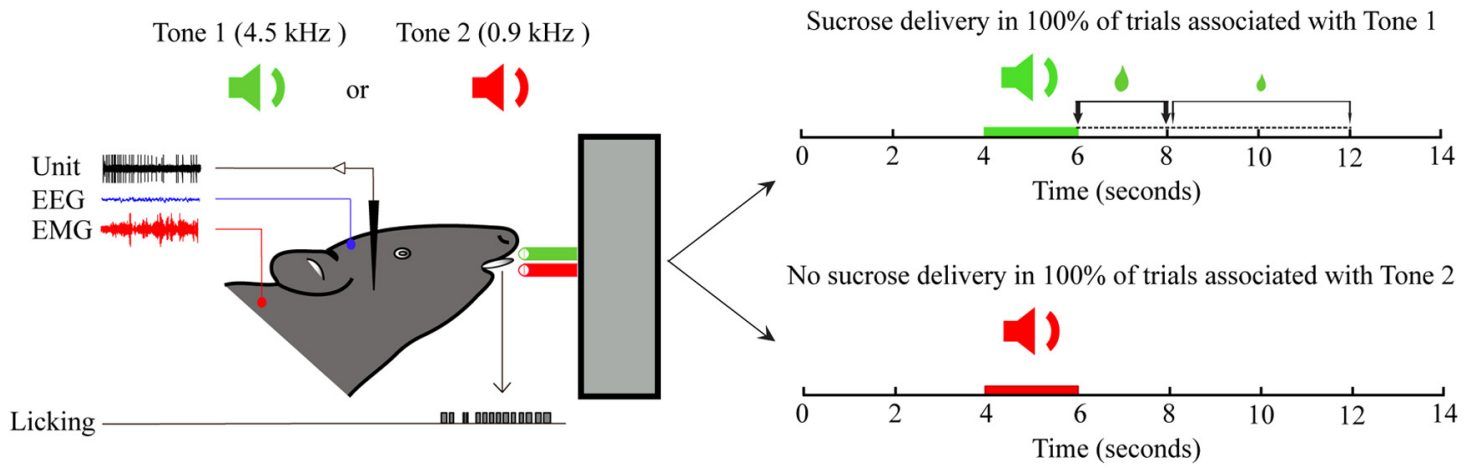

Figure 1. Associative discrimination task. Rats were trained to respond to auditory stimuli of a high-frequency ( $4.5 \mathrm{kHz}$, Tone 1) or low-frequency (0.9 kHz, Tone 2) tone by licking to receive sucrose ( $\mathrm{S}$ in $\boldsymbol{A}$ and $\boldsymbol{B}$ ) after Tone 1 or not licking to avoid quinine ( $Q$ in $\boldsymbol{A}$ ) or no sucrose (NS in $\boldsymbol{B}$ ) after Tone 2 . For data analysis, each behavioral trial was defined as a $14 \mathrm{~s}$ period that included a $4 \mathrm{~s}$ period before tone delivery, a 2 s period during tone, and an $8 \mathrm{~s}$ period after tone delivery. An interval of $10 \pm 2 \mathrm{~s}$ occurred between these behavioral trials. To foster the rat's motivation and response, a bigger drop of sucrose was delivered if the animal responded within the initial $0-2 \mathrm{~s}$ window after the tone than if it responded within the subsequent $2-6 \mathrm{~s}$ window, after which no solution was delivered in response to licking. $A$, With the $S / Q$ procedure, one group of animals was trained with partial reinforcement such that only $75 \%$ of sucrose-associated or quinine-associated trials were reinforced. $\boldsymbol{B}$, With the S/NS procedure, another group of animals was trained to receive full reinforcement (100\%) for sucrose-associated trials and no reinforcement (0\%) for no sucrose-associated trials. The unit discharge was recorded together with EEG and EMG activity and licking. After recording and characterization over several trials, one neuron (per side per animal) was submitted to juxtacellular labeling with $\mathrm{Nb}$ for its immunohistochemical identification.

was incubated overnight at room temperature in both goat anti-Orx A antiserum (1:500; Santa Cruz Biotechnology) and rabbit anti-MCH antiserum (1:2500; Phoenix Pharmaceuticals) and subsequently for $2 \mathrm{~h}$ in Cy3 anti-goat antiserum (1:1000; Jackson ImmunoResearch Laboratories) and Cy5 anti-rabbit antiserum (1:800; Jackson ImmunoResearch Laboratories). The triple-stained sections with $\mathrm{Nb}$ labeled units were viewed using an epifluorescence Leica DMLB microscope equipped with $x-y-z$ motorized stage, digital camera, and fluorescence filters for excitation and emission of the Cy2, Cy3, and Cy5 fluorescence. Multichannel images of Nb-labeled cells were acquired using Neurolucida software (MicroBrightField) and the labeled neurons were mapped onto a computer resident atlas with the aid of the same Neurolucida software.

Data analysis. Electrophysiological data were exported from Neuralynx's data acquisition system to MATLAB (The MathWorks). Each trial was defined within a $14 \mathrm{~s}$ window that contained the $4 \mathrm{~s}$ period before the tone delivery, the $2 \mathrm{~s}$ window during tone delivery, and the $8 \mathrm{~s}$ window after the tone. Unit activity was analyzed for average discharge rate (spikes per second) and instantaneous firing frequency (the reciprocal of the first modal peak of the interspike interval histogram, ISIH) during the before, tone, and after periods in individual trials associated with either Tone 1 or Tone 2 . For examining correlation with unit spike rate, gamma $(30-58 \mathrm{~Hz})$ and delta EEG $(0.5-$ $4.0 \mathrm{~Hz})$ and $\mathrm{EMG}(30-100 \mathrm{~Hz})$ amplitudes were also measured during the before, tone, and after periods. The number of licks was measured during the after period.

Average discharge rates across trials were examined across periods (before, tone and after) and as a function of tone (Tones 1 and 2) and training (S/Q or S/NS) using mixed repeated-measures (RM)-ANOVA together with post hoc repeated or paired comparisons (Systat version 13). Average discharge rates were also correlated with gamma and delta EEG and EMG amplitudes using Pearson correlations with Dunn-Sidakcorrected probabilities for multiple comparisons. Results are expressed in the text as mean \pm SEM.

\section{Results}

\section{Recording, characterizing, and identifying Orx ${ }^{+}$neurons} with a behavioral task

Using the juxtacellular technique, we recorded and labeled neurons within the LH of head-fixed rats during performance of an associative discrimination task. Each rat had previously been habituated to the recording condition and trained to discriminate between auditory cues associated, according to different procedures, either with S/Q or S/NS (Fig. 1). Of 168 successfully recorded units, 105 were recorded in rats trained with the S/Q procedure and 63 units from those trained with the S/NS procedure. Among these units, 84 were submitted to the juxtacellular 
labeling protocol (of one neuron per side) and, of these, 57 neurons $(68 \%)$ were positively labeled with $\mathrm{Nb}\left(\mathrm{Nb}^{+}\right)$. After dual immunostaining for Orx and $\mathrm{MCH}, 11$ $\mathrm{Nb}^{+}$neurons from 11 rats were identified as immunopositive for Orx $\left(\mathrm{Orx}^{+}\right)$and immunonegative for $\mathrm{MCH}\left(\mathrm{MCH}^{-}\right)$ (Fig. 2A). Eight of these units/rats were trained and tested with the $S / Q$ procedure and three with the S/NS procedure. In the entire sample, no $\mathrm{Nb}^{+}$neurons were $\mathrm{MCH}^{+}$. The $\mathrm{Nb}^{+} / \mathrm{Orx}{ }^{+}$neurons were distributed within the $\mathrm{LH}$ and perifornical area (Fig. $2 B$ ).

The $\mathrm{Nb}^{+} / \mathrm{Orx}^{+}$neurons were recorded across randomly ordered trials containing Tone 1 or Tone 2 , which were associated during prior training with either S/Q or S/NS outcomes in different groups of rats. During training with the S/Q procedure, Tone 1 was followed by receipt of sucrose in $75 \%$ of trials and Tone 2 by receipt of quinine in $75 \%$ of trials, when the animal licked within $6 \mathrm{~s}$ (Fig. 1A). During training with the S/NS procedure, Tone 1 was followed by receipt of sucrose in $100 \%$ of trials and Tone 2 followed by "no sucrose" in 100\% of trials, when the animal licked within $6 \mathrm{~s}$ (Fig. $1 B)$. Licking responses to the tone, which occurred within the first $2 \mathrm{~s}$ window after the tone, were rewarded with a larger drop than those which occurred within the subsequent $4 \mathrm{~s}$ window. Given their apparent aversion to quinine, rats learned the discrimination between Tone 1 and 2 with the S/Q procedure very slowly, reaching the criterion of significantly different latencies and percentage responses to the 2 tones only after $\sim 6$ weeks (Movie 1 at http://www.mcgill.ca/neuro/research/researchers/ jones/hassani-et-al-supplemental-information). With no apparent aversion to "no sucrose," rats learned to discriminate between Tone 1 and Tone 2 much more readily with the $\mathrm{S} / \mathrm{NS}$ procedure, reaching the criterion within 3 weeks (Movie 2 at http://www.mcgill.ca/neuro/research/researchers/jones/ hassani-et-al-supplemental-information). After having attained and remained at criterion level responding for $3 \mathrm{~d}$ before testing, rats showed significant behavioral discrimination between Tone 1 and Tone 2 in the two training procedures. Over the $3 \mathrm{~d}$ of pretesting in the 11 rats having the $\mathrm{Nb}^{+} / \mathrm{Orx}^{+}$neurons, there was a significant difference in the latency to licking response between tones $(1.18 \pm 0.29 \mathrm{~s}$ for Tone $1 \mathrm{vs} 2.74 \pm 0.37 \mathrm{~s}$ for Tone 2 ; with two-way RM-ANOVA, $\left.F_{(1,9)}=221.92, p<0.001\right)$, but also in an interaction with training procedure $\left(F_{(1,9)}=6.36, p=\right.$ 0.033 ) because the latencies to both Tone 1 and Tone 2 were, on average, longer with the S/Q than with the S/NS procedure. The longest latency occurred with Tone $2(\mathrm{Q})$ in the $S / Q$ procedure $(3.04 \pm 0.47 \mathrm{~s})$ and the shortest latency with tone $1(\mathrm{~S})$ in the $\mathrm{S} / \mathrm{NS}$ procedure $(0.72 \pm 0.25 \mathrm{~s})$. Nonetheless, across training, the average latency of response to Tone 1 fit within the $2 \mathrm{~s}$ window during which the animal received the bigger drop of sucrose, whereas that to Tone 2 occurred within the later window, during which the animal received a smaller drop of what would be quinine or no sucrose (Fig. $1 A, B$ ). There was also a significant difference in the percentage response between tones $(76.90 \pm 3.90 \%$ for Tone 1 and $67.02 \pm 4.81 \%$ for Tone 2 ; with two-way RMANOVA, $\left.F_{(1,9)}=7.08, p=0.026\right)$, which also differed according to training $\left(F_{(1,9)}=9.97, p=0.012\right)$ because the percentage response to both Tone 1 and Tone 2 was significantly lower with the S/Q than with the S/NS procedure (in post hoc analysis, $p<$ $0.05)$. The lowest percentage response occurred with Tone $2(\mathrm{Q})$ in the S/Q procedure $(61.22 \pm 5.24 \%)$ and the highest percentage response with Tone $1(\mathrm{~S})$ in the $\mathrm{S} / \mathrm{NS}$ procedure $(92.08 \pm 0.90 \%)$. The average number of licks also differed between tones (36.49 \pm 13.85 licks after Tone 1 and $18.74 \pm 9.01$ licks after Tone 2, $F_{(1,8)}=31.30, p=0.001$ with no significant effect or interaction with training using a two-way mixed RM-ANOVA).

In both the S/Q and S/NS procedures during testing, the 11 identified $\mathrm{Nb}^{+} / \mathrm{Orx}^{+}$neurons discharged in a slow, tonic manner (with a range across cells and conditions of $\sim 0-15 \mathrm{~Hz}$ instantaneous firing frequency and $\sim 0-12.0 \mathrm{~Hz}$ average discharge rate), although with variations in the firing pattern and average rate across periods, tones, training, and trials. During the period before the tones ( $4 \mathrm{~s}$ ), neurons discharged at low rates and were completely silent $(0 \mathrm{~Hz})$ in a small proportion of trials $(22 \%)$, whereas during the tones $(2 \mathrm{~s})$, they discharged at relatively high 


\section{$\mathrm{Nb}+/ \mathrm{Orx}+$ neuron discharge rate}
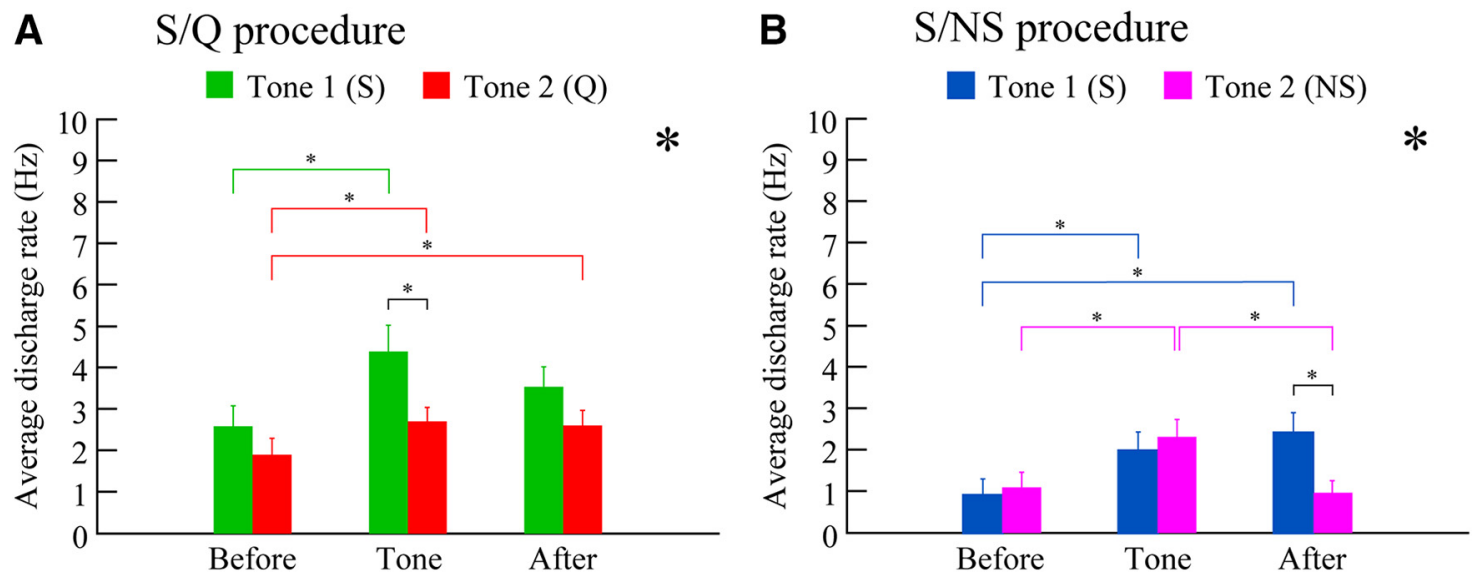

Figure 3. Average discharge rate of $\mathrm{Nb}^{+} / 0 \mathrm{rx}{ }^{+}$neurons with $\mathrm{S} / \mathrm{Q}$ and $\mathrm{S} / \mathrm{NS}$ procedures. The discharge of all $0 \mathrm{rx}$ neurons varied significantly as a function of the period (before, during tone, and after), the tone (Tone 1 or 2$)$, and the training ( $S / Q$ or $S / \mathrm{NS})$. $A$, With the $S / Q$ procedure $\left(n=8\right.$ cells, 57 trials), the discharge rate of $\mathrm{Nb}^{+} / 0 \mathrm{rx}^{+}$neurons varied significantly across periods and tones. The average discharge rate during Tone 1 was significantly higher than that during Tone2, reflecting discrimination of auditory cues associated with appetitive versus aversive valences. B, With the S/NS procedure ( $n=3$ cells, 29 trials), the discharge rate also varied significantly across periods and as a function of tone. The average discharge rate was significantly higher after Tone 1 (S) than after Tone 2 (NS), reflecting learned association with the receipt of appetitive sucrose. ${ }^{*} p<0.05$ for period and or with tone in two-way mixed RM-ANOVAs for each procedure; ${ }^{*} p<0.05$, according to post hoc comparisons; see text.

rates and were almost never silent (1\% of trials) and after the tones $(8 \mathrm{~s})$, they discharged at variable rates and were rarely silent ( $\sim 7 \%$ of trials).

Across all $\mathrm{Nb}^{+} / \mathrm{Orx}^{+}$cells $(n=11,86$ trials), the average discharge rate differed significantly across recording periods (before, during, and after: $\left.F_{(2,170)}=13.88 p<0.001\right)$ with a significant three-way interaction with tone (1 or 2 ) and training (S/Q or S/NS) $\left(F_{(2,164)}=3.39, p=0.036\right.$ in a three-way mixed RM-ANOVA). The responses were thus analyzed in more detail and by post hoc analysis (Fig. 3) for each training procedure (see below).

\section{Discriminative response to tones by Orx neurons with the $\mathrm{S} / \mathrm{Q}$ procedure}

In the $S / Q$ group ( $n=8$ cells, 57 trials), the average discharge rate of $\mathrm{Orx}^{+}$neurons differed significantly across Periods $\left(F_{(2,110)}=\right.$ $8.87, p<0.001)$ and between Tone 1 and Tone $2\left(F_{(1,55)}=4.77\right.$, $p=0.033$, in a two-way mixed RM-ANOVA, with no significant interaction between period and tone) (Fig. $3 A$ ). With Tone 1 ( $n=25$ trials), associated with sucrose, the average discharge rate of $\mathrm{Orx}^{+}$neurons varied significantly across periods $\left(F_{(2,48)}=\right.$ $4.80, p=0.013)$, with the rate before $(2.59 \pm 0.48 \mathrm{~Hz}$; mean \pm SEM) increasing significantly during Tone $1(4.39 \pm 0.62 \mathrm{~Hz}, p<$ $0.05)$ and decreasing yet remaining relatively high after Tone 1 (S) $(3.54 \pm 0.47 \mathrm{~Hz}$, not being significantly different from during tone, $p=0.148$ or Before, $p=0.119$ ) (Fig. $3 A$ ). With Tone 2 associated with quinine ( $n=32$ trials), the average discharge rate also varied significantly across periods $\left(F_{(2,62)}=3.81, p=0.027\right)$, the rate before $(1.91 \pm 0.39 \mathrm{~Hz})$ increasing significantly during Tone $2(2.71 \pm 0.33 \mathrm{~Hz}, p<0.05)$ and remaining higher after Tone $2(\mathrm{Q})(2.61 \pm 0.36 \mathrm{~Hz}, p<0.05$, relative to before) (Fig. $3 A)$. In a few trials $(9 \%)$, cells ceased firing altogether $(0 \mathrm{~Hz})$ after Tone $2(\mathrm{Q})$. Between tones, the average discharge rate during Tone 1 was significantly higher than that during Tone $2\left(F_{(1,55)}=\right.$ 6.47, $p=0.014)$, suggesting a stronger learned appetitive response. The rate was not significantly different between the two tones during the after period $\left(F_{(1,55)}=2.57, p=0.115\right)$ (Fig. $\left.3 A\right)$.

As shown for a representative cell with the $S / Q$ procedure (Fig. 4), individual $\mathrm{Nb}^{+} / \mathrm{Orx}^{+}$neurons most commonly discharged at a very low rate before the tones, increased their rate during the tones and continued to discharge after the tones. Across cells, however, the degree of change in discharge varied. As for the cell in Figure 4, the majority (5/8) of cells increased their discharge rate during Tone 1 to a greater degree than during Tone 2 and some (3/8) continued to discharge at a high rate after Tone $1(\mathrm{~S})$ and not after Tone $2(\mathrm{Q})$, showing a discharge profile suggestive of an appetitive response. However, not all Orx neurons manifested such a clear profile with the S/Q procedure. Variations in response across periods, tones, or trials, however, appeared to be additionally associated with variations in EEG and EMG activity, such that high rates of firing were associated with fast EEG activity and high EMG amplitude and low rates with slower EEG activity and low EMG amplitude (Fig. 5). For most individual cells, there was a positive correlation across trials and periods of average discharge rate with fast gamma EEG activity (5 cells, mean \pm SEM, $r=0.58 \pm 0.11)$ and/or a negative correlation with slow delta EEG activity ( 7 cells, $r=-0.71 \pm-0.07$ ). There was also a positive correlation with EMG amplitude (6 cells, $r=$ $0.68 \pm 0.08)$, suggesting that Orx unit discharge also varied in a manner related to vigilance or attention and arousal (see below).

\section{Discriminative response to tones by Orx neurons with the S/NS procedure}

In the S/NS group ( $n=3$ neurons, 29 trials), the average discharge rate of $\mathrm{Orx}^{+}$neurons differed significantly across periods (before, tone, after: $\left.F_{(2,54)}=7.52, p=0.001\right)$ with a significant interaction with Tone 1 or $2\left(F_{(2,54)}=5.54, p=0.006\right.$ in a twoway mixed RM-ANOVA) (Fig. $3 B$ ). Overall, with Tone 1 trials associated with sucrose reward ( $n=14$ trials), the average discharge rate varied significantly across periods $\left(F_{(2,26)}=6.22, p=\right.$ $0.006)$ and increased significantly from before $(0.91 \pm 0.37 \mathrm{~Hz}$, $n=14)$ to during Tone $1(1.98 \pm 0.44 \mathrm{~Hz}, p<0.05)$ and after Tone 1 (S) $(2.42 \pm 0.47 \mathrm{~Hz}, p<0.05$, relative to before) (Fig. $3 B)$. With Tone 2 trials associated with no sucrose reward $(n=15$ trials), the average discharge rate varied significantly across periods $\left(F_{(2,28)}=6.85, p=0.004\right)$ and increased significantly from before $(1.1 \pm 0.35 \mathrm{~Hz}, n=15)$ and during Tone $2(2.31 \pm 0.4 \mathrm{~Hz}$, 


\section{$\mathrm{Nb}+/$ Orx + neuron: $\mathrm{S} / \mathrm{Q}$}

A
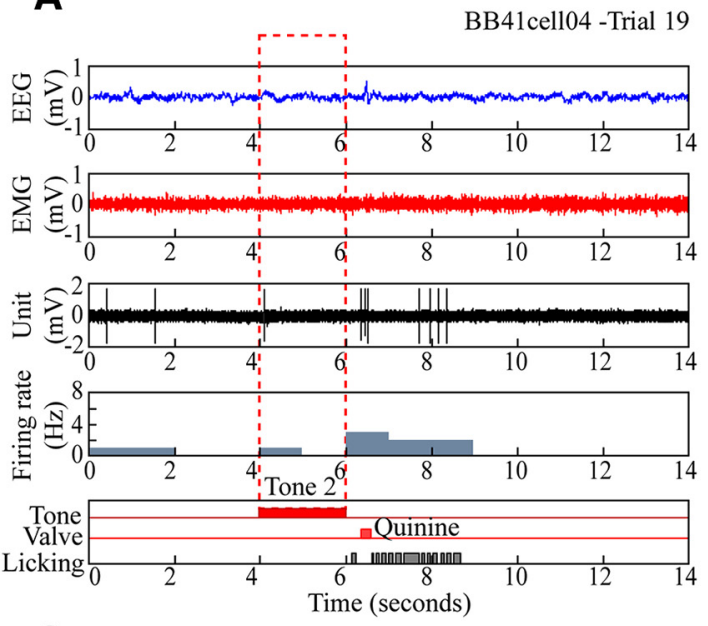

C

BB41cell04 -Trial 22
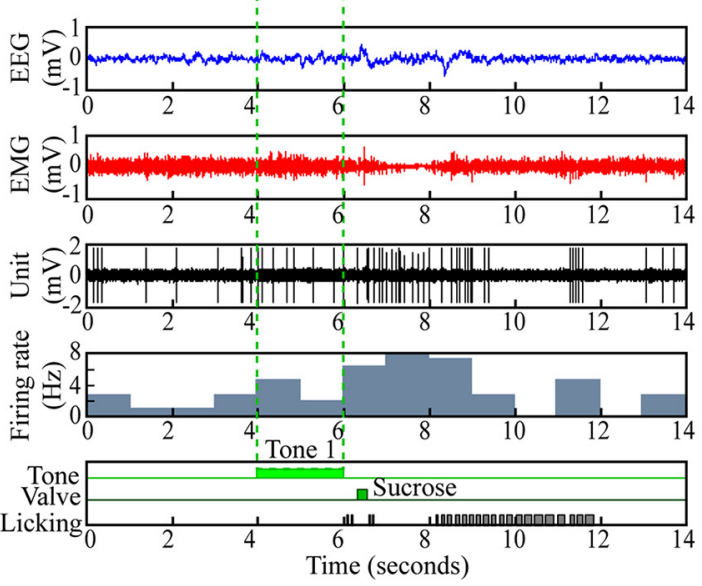

B
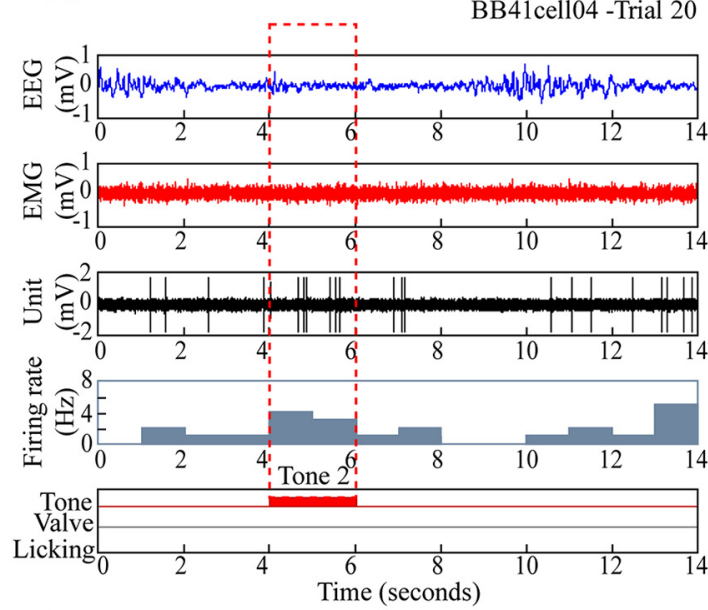

D
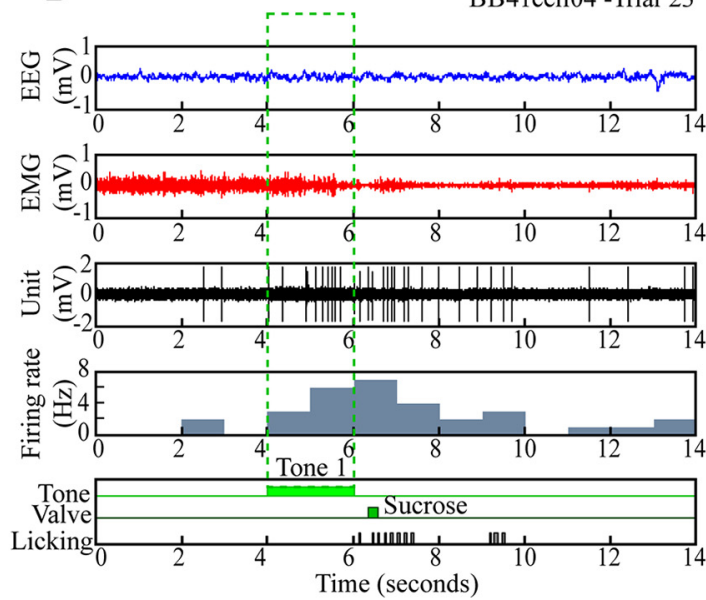

Figure 4. Discharge of $\mathrm{Nb}^{+} / 0 \mathrm{rx}{ }^{+}$neuron during $\mathrm{S} / \mathrm{Q}$ discrimination task. Unit firing of representative $\mathrm{Nb}^{+} / 0 \mathrm{rx}^{+}$neuron (\#BB41cell04 illustrated in Fig. 2) shown along with EEG, EMG, and licking during four sequential $Q$ and $S$ trials. $A, B$, In quinine-rewarded trials, the neuron discharged at a low rate before the tone, minimally or moderately during Tone 2 , and at a moderate rate after Tone 2 (Q), when the rat licked and received a quinine drop (valve) in one trial. The unit appeared to fire at higher rates in association with fast EEG activity. $C, D$, In sucrose-rewarded trials, the neuron discharged at a moderate rate before and higher rate during Tone 1 to reach its highest rate after Tone $1(S)$, when the rat licked with short latency to receive a large drop of sucrose. Across all $S$ and $Q$ trials $(n=10)$ for this unit, the average discharge rate was positively correlated with gamma EEG amplitude $(r=0.401)$ and EMG amplitude $(r=0.693)$.

$p<0.05)$, but decreased significantly after Tone 2 (NS) $(0.97 \pm$ $0.28 \mathrm{~Hz}, p<0.05$, relative to during tone) (Fig. $3 B$ ). In a small proportion of trials $(13 \%)$, units ceased firing altogether $(0 \mathrm{~Hz})$ after Tone 2. The discharge rate did not differ between Tone 1 and Tone 2 during the tones, but was significantly higher after Tone 1 (S) associated with sucrose than after Tone 2 (NS) associated with no sucrose $\left(F_{(1,27)}=7.38, p=0.012\right)$ (Fig. $\left.3 B\right)$. These results suggested a reward associated response by the Orx neurons.

As shown for the cell in Figure 6, all of the $\mathrm{Nb}^{+} / \mathrm{Orx}^{+}$cells in the S/NS group (3/3) increased their average discharge during Tone 1 and continued to fire at high rates after Tone 1 (S), when sucrose reward was delivered with the licking response, thus suggesting a profile characteristic of an appetitive and reward response for both the conditioned and unconditioned reward stimuli. They also tended to increase their discharge in response to Tone 2, but then decreased their discharge after Tone 2 (NS) when no sucrose was delivered. Across periods, tones, and trials, however, the discharge rate appeared to vary additionally in association with variation in EEG and EMG activity (Fig. 5). For most cells, there was a positive correlation of average discharge rate with fast gamma EEG activity (2 cells, mean $\pm \mathrm{SEM}, r=0.77 \pm 0.11)$ and, for all cells, a negative correlation with slow delta EEG activity ( 3 cells, $r=-0.64 \pm 0.05$ ). There was also a positive correlation with EMG amplitude (3 cells, $r=0.64 \pm 0.09$ ), suggesting that unit discharge also varied in a manner related to vigilance or attention and arousal (see below).

In the $\mathrm{S} / \mathrm{NS}$ (as well as $\mathrm{S} / \mathrm{Q}$ ) procedure, the sucrose (or quinine) was omitted for a number of trials during testing such that the effect of consumption could be assessed on discharge during the after period. With S/NS, there was no significant effect on after Tone 1 (S) discharge of omission of the sucrose during testing (with mixed RMANOVA, $\left.F_{(1,12)}=0.01, p=0.910\right)$. This lack of effect was evident in individual $\mathrm{Nb}^{+} / \mathrm{Orx}^{+}$cells, such as that shown in Figure 7. Similarly, with the S/Q procedure, there was no significant effect on after tone discharge of omission of sucrose and quinine during testing $\left(F_{(1,53)}=0.86, p=0.360\right.$ or significant interaction with tone, $F_{(1,53)}$ $=1.62, p=0.210)$. These results suggest that the Orx neuron discharge rate after Tone 1 (S) (or Tone 2 (Q or NS) during testing was due to the conditioned stimulus and response associated with the outcome during training. 
Scatterplots of $\mathrm{Nb}+/ \mathrm{Orx}+$ neuron discharge rate

A
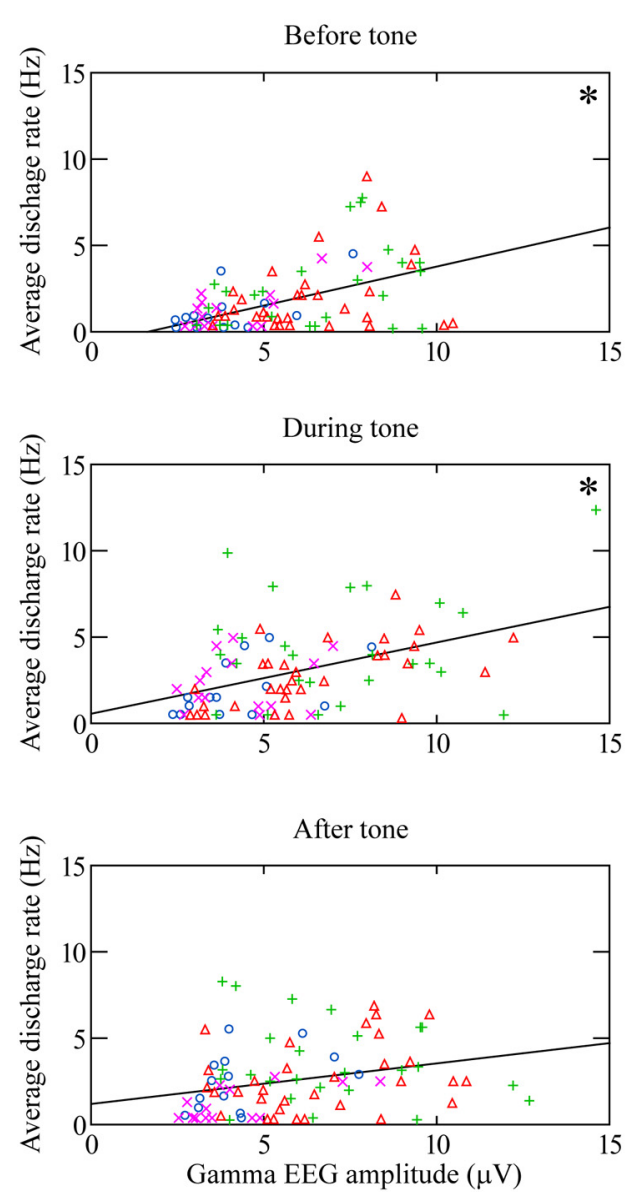

B With EMG amplitude
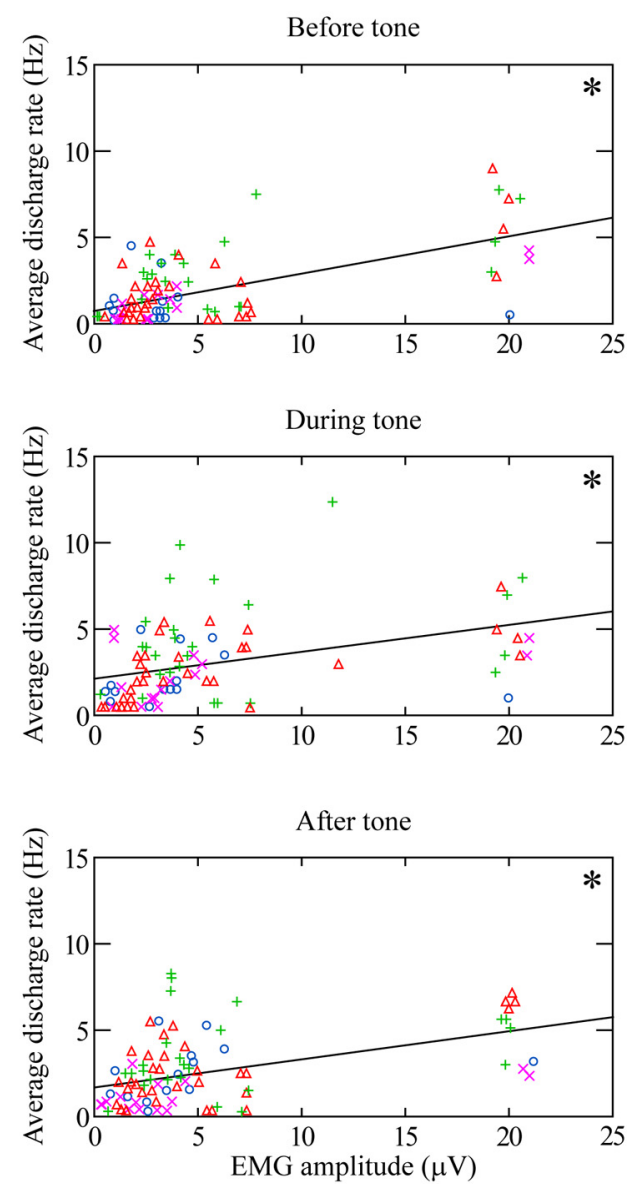

$+\mathrm{S} / \mathrm{Q}:$ Tone $1(\mathrm{~S})$

$\triangle \mathrm{S} / \mathrm{Q}:$ Tone $2(\mathrm{Q})$

- S/NS: Tone 1 (S)

$\times$ S/NS: Tone 2 (NS)

Figure 5. Correlations of $\mathrm{Nb}^{+} / \mathrm{Orx}^{+}$neuron discharge with EEG gamma or EMG amplitude. Scatterplots are presented for the three periods (before tone, during tone, and after tone) and include data of individual trials $(n=86)$ from S/Q Tone 1 (S) (green plusses, 25), S/Q Tone 2 (Q) (red triangles, 32), S/NS Tone 1 (S) (blue circles, 14), and S/NS Tone 2 (NS) (magenta crosses, 15). A, As shown by the linear regression lines for all trials per period, the unit discharge rate was significantly positively correlated with gamma EEG amplitude during the before and tone periods. $\boldsymbol{B}$, The unit discharge rate was also positively correlated with EMG amplitude during all three periods. ${ }^{*} p<0.05$ according to Pearson's correlations with Dunn-Sidak-corrected probabilities; see text.

\section{Correlation of $\mathrm{Orx}^{+}$neuron discharge with gamma EEG and EMG}

For all Orx ${ }^{+}$cells $(n=11)$ across tones, training, and trials $(n=$ 86 ), the discharge rate was positively and significantly correlated (using two set pairwise Pearson correlations with Dunn-Sidakcorrected probabilities for before, tone, and after Periods, $p<$ $0.003)$ with gamma EEG amplitude before $(r=0.47)$ and during tone $(r=0.45)$ (though not significantly after, $r=0.27, p=$ $0.197)$ (Fig. $5 A)$ and EMG amplitude before $(r=0.63)$, during tone $(r=0.39)$ and after $(r=0.46)$ (Fig. $5 B)$. These results indicate covariation of the discharge rate with cortical activation and behavioral arousal and suggest responses related to vigilance, attention, and/or arousal. It is of note that, across tones, training, and trials, fast gamma EEG activity did not vary significantly as a function of period (in a three-way mixed RMANOVA with tone and training), yet did with training $\left(F_{(1,83)}=\right.$ 418.41, $p<0.001)$, being higher during the S/Q procedure than $\mathrm{S} / \mathrm{NS}$. Slow delta EEG activity also varied with training $\left(F_{(1,83)}=\right.$
8.67, $p=0.004$ ), being lower during the S/Q procedure than $\mathrm{S} / \mathrm{NS}$. These results suggest that animals were more relaxed or in a more quiet wake state during the S/NS procedure than during the $S / Q$ procedure. EMG amplitude did vary significantly across periods $\left(F_{(2,166)}=9.78, p<0.001\right.$ in a three-way mixed RMANOVA with tone and training) for which there were no significant main effects, although there was a trend for a significant three-way interaction $\left(F_{(2,166)}=3.04, p=0.054\right)$, being significantly higher during tone and after tone than before $(p<0.001)$. There was also a significant correlation between discharge rate and number of licking responses after the tone $(r=0.324, p=$ $0.007)$ suggestive of an association with motor activity as well.

\section{Response of $\mathrm{Orx}^{-}$cells with $\mathrm{S} / \mathrm{Q}$ and $\mathrm{S} / \mathrm{NS}$ procedures}

$\mathrm{The}^{+}{ }^{+} / \mathrm{Orx}^{-}$cells $(n=46)$, which were also located in the $\mathrm{LH}$, were highly heterogeneous in their discharge properties. They included slow firing $(<15 \mathrm{~Hz}, n=20)$ and fast firing $(>15 \mathrm{~Hz}$ with a maximum of $50 \mathrm{~Hz}, n=26$ ) neurons according to their 
$\mathrm{Nb}+/ \mathrm{Orx}+$ neuron: $\mathrm{S} / \mathrm{NS}$

A
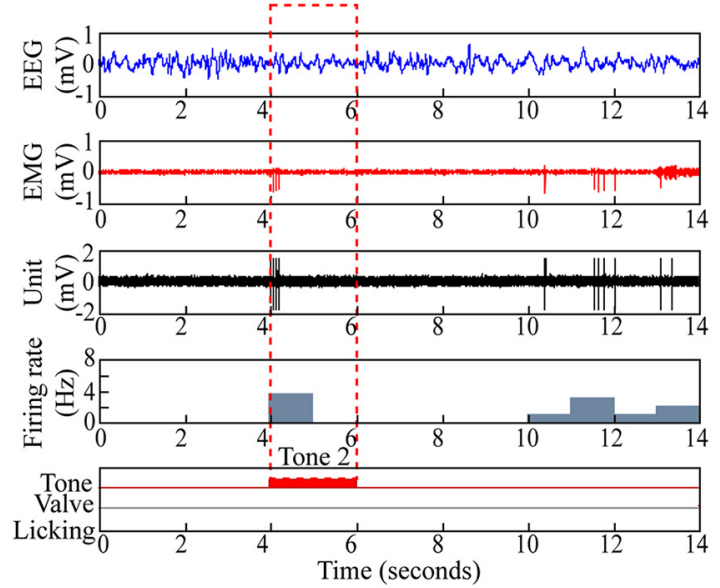

C

BB46D2cell01-Trial 9
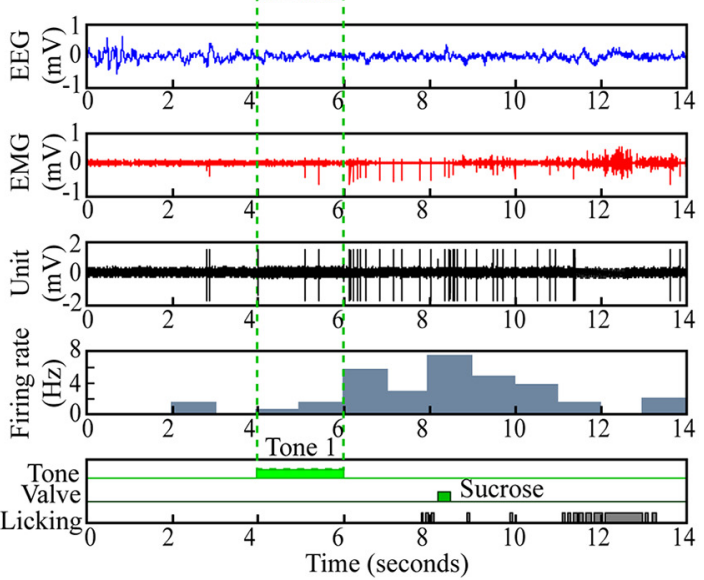

B
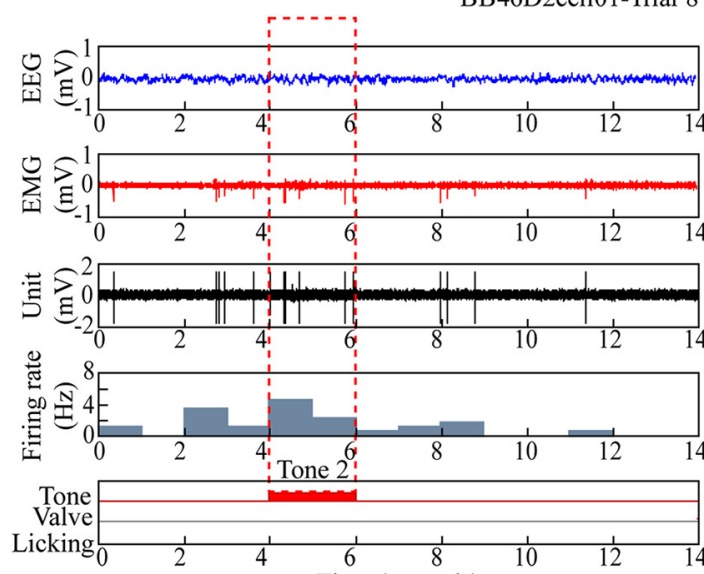
Time (seconds)

D

BB46D2cell01-Trial 11
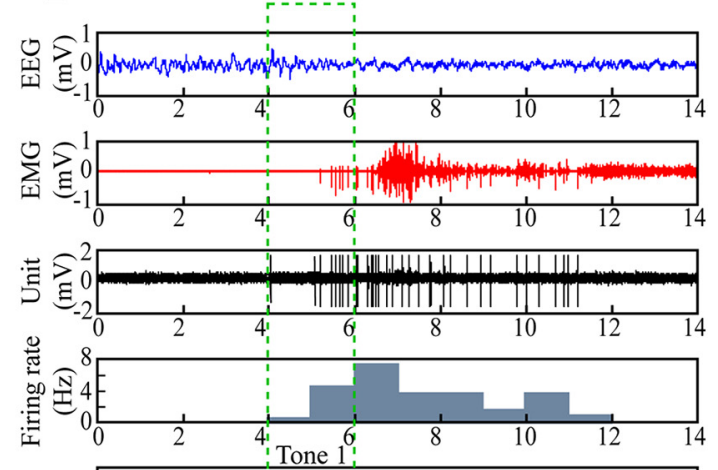

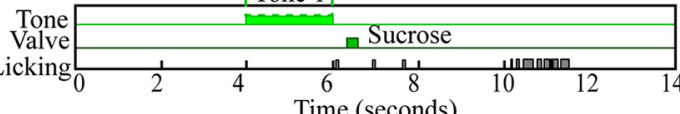

Figure 6. Discharge of $\mathrm{Nb}^{+} / 0 \mathrm{rx}{ }^{+}$neuron during $\mathrm{S} / \mathrm{NS}$ discrimination task. Unit firing of representative $\mathrm{Nb}^{+} / 0 \mathrm{rx}{ }^{+}$neuron (\#BB46D2cell01) shown along with EEG, EMG, and licking response during four sequential trials. $\boldsymbol{A}, \boldsymbol{B}$, In nonrewarded (no sucrose) Tone 2 trials, the unit discharged minimally before, moderately during Tone 2, and minimally after Tone 2 (NS), when the rat did not lick. $\boldsymbol{C}, \boldsymbol{D}$, In sucrose-rewarded Tone 1 trials, the unit discharged minimally before, moderately during Tone 1 , and at a high rate after Tone 1 (S), when the rat licked to receive a small drop (in the later $2-6 \mathrm{~s}$ window in $\boldsymbol{C}$ ) or large drop (within the initial $0-2 \mathrm{~s}$ window in $\boldsymbol{D}$ ) of sucrose. The unit appeared to discharge at highest rates in association with fast EEG activity and EMG activity. Across all trials $(n=18)$, the average discharge rate was positively correlated with gamma EEG amplitude $(r=0.884)$ and EMG amplitude $(r=0.674)$.

instantaneous firing frequency, which discharged at average rates of $0-44 \mathrm{~Hz}$ across periods. Across all Orx ${ }^{-}$cells $(n=46$ with 375 trials), there was a trend toward differences in average discharge rate between periods (before $=6.86 \pm 0.35 \mathrm{~Hz}$, tone $=7.41 \pm$ $0.40 \mathrm{~Hz}$, after $=6.92 \pm 0.37 \mathrm{~Hz}$; with a three-way RM-ANOVA with tone and training, $\left.F_{(2,742)}=2.63, p=0.073\right)$ and a significant interaction with tone $\left(F_{(2,742)}=3.45, p=0.032\right)$ but not with training.

In examining individual $\mathrm{Orx}^{-}$cell responses with the $\mathrm{S} / \mathrm{Q}$ and S/NS procedures, considerable variability was found. According to average discharge rate across periods and tones among 27 cells with the S/Q procedure, 6 cells discharged in a manner suggestive of an appetitive or reward response, 4 an aversive response, and 17 an indifferent response. Among 19 cells with the S/NS procedure, 6 discharged in a manner suggestive of an appetitive or reward response, 0 of an aversive response, and 13 an indifferent response.

\section{Discussion}

The present study shows that Orx neurons increase their discharge during presentation of conditioned auditory cues and do so to a greater degree during or after the cue associated with rewards than during or after that associated with aversive outcomes. They also vary their discharge in association with cortical activation and behavioral arousal, indicating that Orx neurons convey signals concerning the occurrence and valence of sensory cues according to their learned outcome while responding to and promoting cortical activation and behavioral arousal along with motor responses in the appropriate context.

Using juxtacellular recording and labeling in head-fixed behaving rats, this is the first study to record from immunohistochemically identified Orx neurons during the performance of an associative discrimination task. Previous studies that have suggested a role for Orx neurons in reward mechanisms have used c-Fos expression as a reflection of neural activity after a place preference task (Harris et al., 2005). However, histochemical staining for c-Fos protein does not allow the temporal precision necessary to assess neural activity or even to judge the presence versus the absence of neural discharge (Luckman et al., 1994; Guo et al., 2007). It is also noteworthy that expression of cAMP response element-binding protein (CREB) has been reported in 


\section{$\mathrm{Nb}+/ \mathrm{Orx}+$ neuron: $\mathrm{S} / \mathrm{NS}$ with sucrose Omission}

A

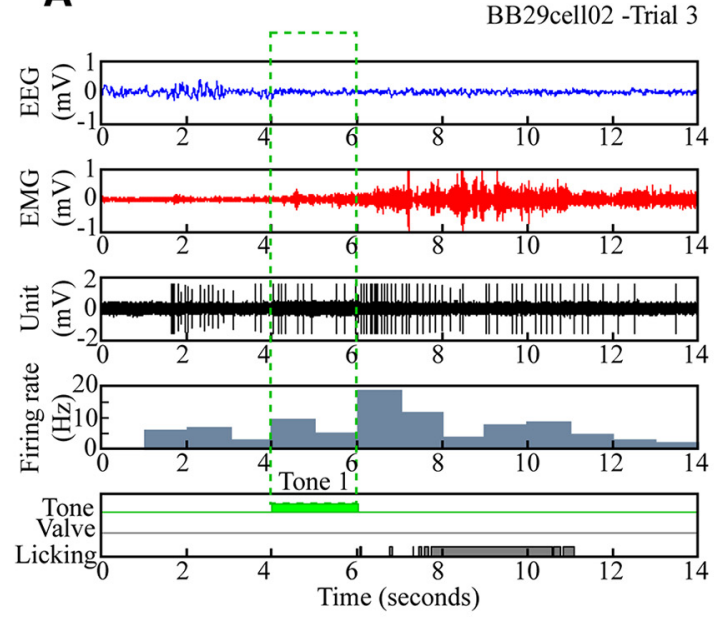

\section{C}
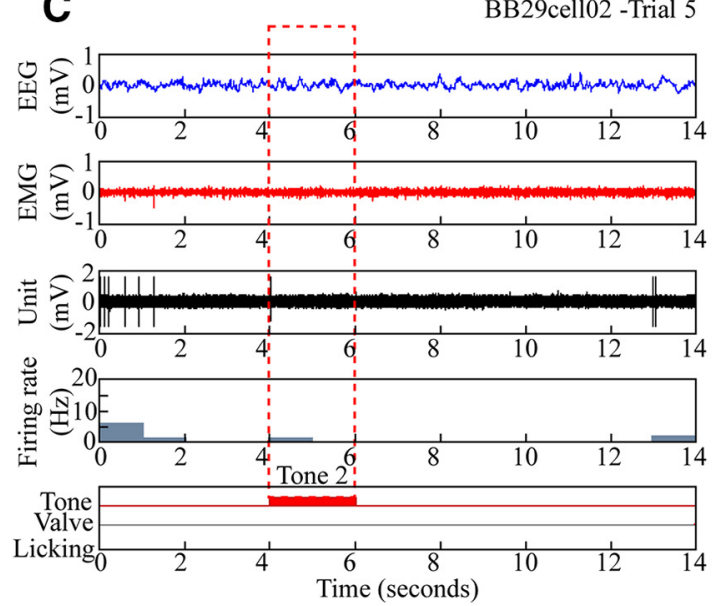

B
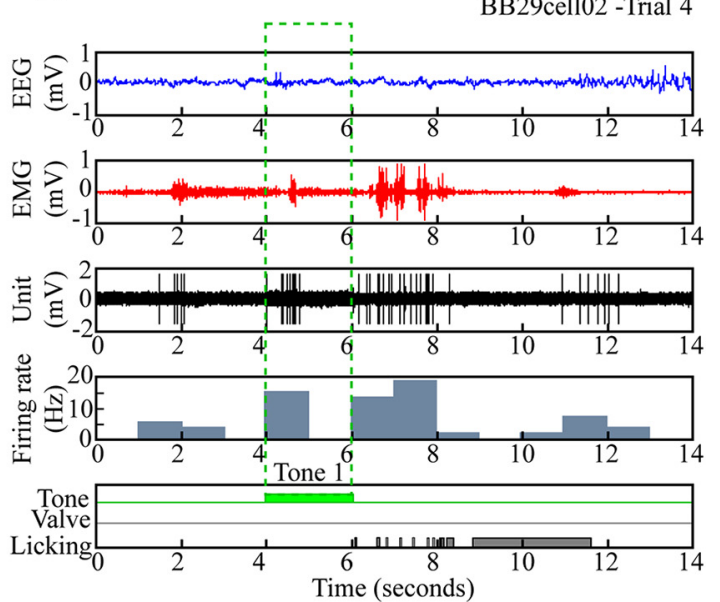

D
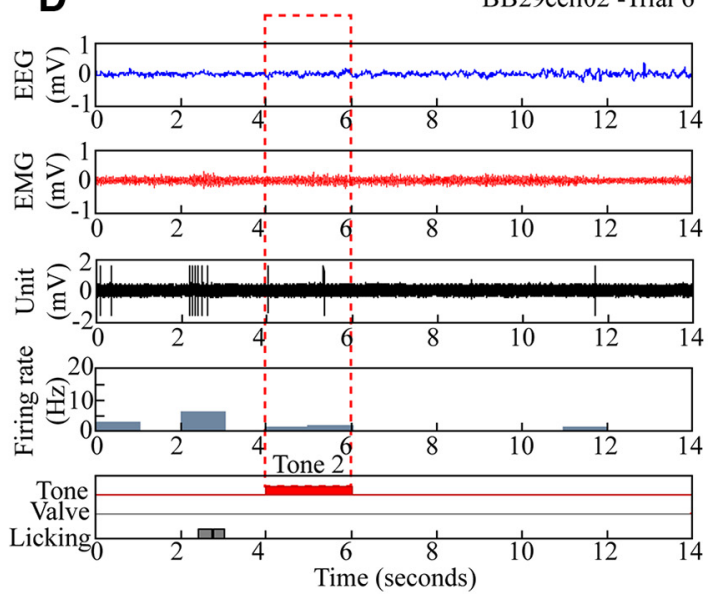

Figure 7. Discharge of $\mathrm{Nb}^{+} / 0 \mathrm{rx}^{+}$neuron during omission trials after training with S/NS procedure. The discharge of a representative Nb ${ }^{+} / 0 \mathrm{rx}{ }^{+}(\# \mathrm{BB} 29 \mathrm{cell02})$ neuron is shown, along with the EEG, EMG, and licking response during four sequential trials. $\boldsymbol{A}, \boldsymbol{B}$, With expected sucrose-rewarded trials, the unit discharged at moderate rates before, increased rates during Tone 1 , and high rates after Tone $1(S)$, when the rat licked despite experimental omission of the sucrose. $\boldsymbol{C}, \boldsymbol{D}$, With expected nonrewarded trials of no sucrose, the unit discharged at moderate rates before and virtually not at all during Tone 2 and after Tone 2 (NS), when the rat did not lick. The unit appeared to discharge at its highest rates in association with fast EEG and EMG activity. Across trials ( $n=8$ ), the average discharge rate was positively correlated with gamma EEG amplitude $(r=0.659)$ and EMG amplitude $(r=0.467)$.

$\mathrm{MCH}$ neurons in association with food deprivation, suggesting that they too would become active under these conditions to stimulate feeding (Georgescu et al., 2005). However, in our previous juxtacellular recording study of identified $\mathrm{MCH}$ neurons in naturally sleeping-waking rats, we did not find any Nb-labeled neurons that discharged during waking to be $\mathrm{MCH}^{+}$, but rather found that all $\mathrm{Nb}$-labeled $\mathrm{MCH}^{+}$neurons were silent during waking and only discharged during sleep, particularly REM sleep with muscle atonia (Hassani et al., 2009). Similarly, in the present study under conditions of food and water restriction and with a task that provided sucrose reward to waking rats, we did not find any discharging, $\mathrm{Nb}$-labeled neurons that were $\mathrm{MCH}^{+}$. According to our evidence, $\mathrm{MCH}$ neurons thus do not appear to participate in appetitive behavior or feeding or even to be active during waking. In contrast, based on both the present study and our previous studies (Lee et al., 2005), Orx neurons appear to participate in appetitive learning and behavior along with the cortical activation and behavioral arousal of waking.

As reflected in the average discharge rate across neurons and trials in the two different procedures, the majority of Orx neurons discharged at a higher rate in association with the auditory cue associated with appetitive sucrose than with that associated with aversive quinine in the $S / Q$ procedure and continued to fire at a higher rate after the cue associated with receipt of sucrose than after that associated with no sucrose in the S/NS procedure. These results indicate that Orx neurons show a profile of appetitive or reward response. Since the early studies of Olds and colleagues (Olds, 1976), the LH has been known as an area that supports electrical self-stimulation along with feeding. In early single unit recording studies in monkeys, it was demonstrated that some neurons in the $\mathrm{LH}$ that respond to brain selfstimulation also discharge with the sight, taste, and consumption of food, and are thus considered to be characteristic of reward neurons (Rolls et al., 1980). In rats, a major proportion of neurons in the LH were found to discharge in association with intracranial self-stimulation or glucose and to discriminate cues associated with these appetitive rewards versus those with aversive reinforcements of electrical shock or tail pinch (Ono et al., 1985; Nakamura et al., 1987). Here, we present evidence that Orx neurons, which represent $\sim 2300$ neurons in the LH (Henny and Jones, 2006), comprise a contingent of the reward neurons in the $\mathrm{LH}$. With juxtacellular recording, 
which clearly distinguishes single cells and sample cells of all sizes (Pinault, 1996), and the procedures, which used sucrose and quinine or no sucrose as outcomes, we actually found here a greater proportion of $\mathrm{Orx}^{+}$neurons than of $\mathrm{Orx}^{-}$neurons in the LH that discharged in a manner suggestive of appetitive or reward responses.

Although Orx neurons discharged at a higher rate in association with appetitive cues and rewards than with the aversive ones, they were rarely completely silent during presentation of the aversive cues or their outcomes, indicating a selectivity but not specificity for appetitive learning and response. In fact, from our previous studies of unit activity across the sleep-wake cycle, Orx neurons only appear to remain silent during sleep (Lee et al., 2005). Here, the average discharge rates recorded during the task were mostly in the range previously recorded during active waking (mean $3.17 \mathrm{~Hz}$, with $95 \%$ confidence intervals from 1.15-5.19 $\mathrm{Hz}$ ), which is marked by high gamma EEG and EMG activity (Lee et al., 2005). Only during the S/NS procedure after Tone 2 with no sucrose did rates fall (mean $0.97 \mathrm{~Hz}$ ) into the range previously recorded during quiet waking (mean $0.64 \mathrm{~Hz}$, with $95 \%$ confidence intervals from $-0.08-1.21 \mathrm{~Hz}$ ) (Lee et al., 2005), which is marked by low gamma EEG and EMG activity, indicating a minimal level of attention and arousal under those conditions (Maloney et al., 1997). It also appeared that such low discharge rates with the S/NS procedure were associated with low gamma activity and higher delta activity, suggesting a more quiet waking state with this procedure compared with the S/Q procedure, which involved exposure to aversive quinine. Based upon results using c-Fos expression as a reflection of neural activity, it was claimed previously that Orx neurons in the LH are active in anticipation or receipt of positive reward, including food and drugs, but not when exposed to novel or aversive stimuli and thus proposed that they selectively mediate reward (Harris et al., 2005). In contrast, it was proposed that Orx neurons in the perifornical area and dorsomedial nucleus are active under the latter conditions and mediate arousal and/or stress (Harris and Aston-Jones, 2006). Our results do not support such a dichotomy because the neurons recorded here in the $\mathrm{LH}$ and perifornical area discharged in response to cues of positive and negative valence, although at different rates. Moreover, the discharge rate of the Orx neurons in the LH was positively correlated with gamma EEG activity, indicative of cortical activation, and EMG activity, indicative of behavioral arousal. We thus conclude that Orx neurons in the LH, including the perifornical area, can both respond to and promote cortical activation and behavioral arousal with muscle tone in association with salient cues and responses, particularly appetitive ones. Such results would support a role for Orx neurons in maintaining attention and arousal with muscle tone during certain behaviors and conditions, particularly those involving excitement with appetitive or positive emotion, such as with feeding in dogs and laughter in humans, when in the absence of Orx neurons or their receptors, narcolepsy-cataplexy is most readily triggered (Reid et al., 1994; Nishino and Mignot, 2011; Overeem et al., 2011; Blouin et al., 2013). The latter pathology could in part reflect an imbalance between orexinergic and cholinergic systems that is manifest with certain behaviors and conditions for which both systems are normally engaged during waking (Nishino et al., 1995; Nishino and Mignot, 1997; Brischoux et al., 2008; Jones, 2008).

There is considerable evidence to show that Orx also plays a role in stress and fear and in the hormonal and cardiovascular responses, along with heightened arousal that accompany them (Winsky-Sommerer et al., 2004; Boutrel et al., 2005; Li et al.,
2013; Chen et al., 2014; Giardino and de Lecea, 2014; Mahler et al., 2014; Bonnavion et al., 2015). Working under conditions in which rats were habituated to head fixation and the behavioral learning procedure, we could not assess here how Orx neurons would respond to stress or fear. However, the correlation of their discharge rate with cortical gamma activity and peripheral muscle activity would suggest that the Orx neurons could well discharge at higher rates with such heightened arousal, such as may have occurred with the S/Q procedure to a greater degree than with the S/NS procedure, as judged by average levels of gamma/ delta EEG and EMG amplitudes. Such an association could explain how narcoleptic patients lacking Orx, also experience narcolepsy-cataplexy during conditions of excitement and strong emotion, albeit at lower frequencies, other than laughter (Nishino and Mignot, 2011; Overeem et al., 2011).

In the early studies of reward neurons in the $\mathrm{LH}$, it was found that their valence-specific discharge depended upon input from forebrain and brainstem (Olds, 1976; Nakamura et al., 1987), including input from the ventral tegmentum, where dopamine neurons are located and have been shown to discharge in association with appetitive rewards (Mirenowicz and Schultz, 1996; Schultz, 2007). The present results would support theories that Orx neurons can fulfill a role in appetitive learning and responses in part through interaction with dopamine neurons in the ventral tegmental area. Orx neurons are innervated by dopamine neurons (Yoshida et al., 2006) and project back upon dopamine neurons in the ventral tegmental area (Fadel and Deutch, 2002; Balcita-Pedicino and Sesack, 2007). Behavioral and electrophysiological evidence has supported a role for Orx in selectively facilitating discharge of dopamine neurons in association with highly salient positive reinforcers (Borgland et al., 2009).

In conclusion, the present results indicate that Orx neurons discriminate cues associated with appetitive versus aversive outcomes, such as to respond maximally to conditioned and primary rewards. Their correlated discharge with high-frequency, gamma EEG activity and EMG activity also indicates that they can respond to and promote cortical activation, muscle tone, and motor activity with learned adaptive behavioral responses.

\section{Notes}

Supplemental material for this article is available at http:/www.mcgill.ca/neuro/ research/researchers/jones/hassani-et-al-supplemental-information. Shown are videos of a rat trained and submitted to the S/Q procedure (Movie 1) and a rat trained and submitted to the S/NS procedure (Movie 2). This material has not been peer reviewed.

\section{References}

Adamantidis AR, Zhang F, Aravanis AM, Deisseroth K, de Lecea L (2007) Neural substrates of awakening probed with optogenetic control of hypocretin neurons. Nature 450:420-424. CrossRef Medline

Balcita-Pedicino JJ, Sesack SR (2007) Orexin axons in the rat ventral tegmental area synapse infrequently onto dopamine and gamma-aminobutyric acid neurons. J Comp Neurol 503:668-684. CrossRef Medline

Black SW, Morairty SR, Fisher SP, Chen TM, Warrier DR, Kilduff TS (2013) Almorexant promotes sleep and exacerbates cataplexy in a murine model of narcolepsy. Sleep 36:325-336. Medline

Blouin AM, Fried I, Wilson CL, Staba RJ, Behnke EJ, Lam HA, Maidment NT, Karlsson KÆ, Lapierre JL, Siegel JM (2013) Human hypocretin and melanin-concentrating hormone levels are linked to emotion and social interaction. Nat Commun 4:1547. CrossRef Medline

Bonnavion P, Jackson AC, Carter ME, de Lecea L (2015) Antagonistic interplay between hypocretin and leptin in the lateral hypothalamus regulates stress responses. Nat Commun 6:6266. CrossRef Medline

Borgland SL, Chang SJ, Bowers MS, Thompson JL, Vittoz N, Floresco SB, Chou J, Chen BT, Bonci A (2009) Orexin A/hypocretin-1 selectively promotes motivation for positive reinforcers. J Neurosci 29:11215-11225. CrossRef Medline 
Boutrel B, Kenny PJ, Specio SE, Martin-Fardon R, Markou A, Koob GF, de Lecea L (2005) Role for hypocretin in mediating stress-induced reinstatement of cocaine-seeking behavior. Proc Natl Acad Sci U S A 102: 19168-19173. CrossRef Medline

Brischoux F, Mainville L, Jones BE (2008) Muscarinic-2 and orexin-2 receptors on GABAergic and other neurons in the rat mesopontine tegmentum and their potential role in sleep-wake state control. J Comp Neurol 510: 607-630. CrossRef Medline

Chemelli RM, Willie JT, Sinton CM, Elmquist JK, Scammell T, Lee C, Richardson JA, Williams SC, Xiong Y, Kisanuki Y, Fitch TE, Nakazato M, Hammer RE, Saper CB, Yanagisawa M (1999) Narcolepsy in orexin knock-out mice: molecular genetics of sleep regulation. Cell 98: 437-451. CrossRef Medline

Chen X, Wang H, Lin Z, Li S, Li Y, Bergen HT, Vrontakis ME, Kirouac GJ (2014) Orexins (hypocretins) contribute to fear and avoidance in rats exposed to a single episode of footshocks. Brain Struct Funct 219: 2103-2118. CrossRef Medline

Cowles J, Pennington L (1943) An improved conditioning technique for determining auditory acuity of the rat. J Psychol 5:41-47.

Dube W, Callahan T, McIlvane W (1993) Serial reversals of concurrent auditory discrimination in rats. Psychological Record 43:429-441.

Fadel J, Deutch AY (2002) Anatomical substrates of orexin-dopamine interactions: lateral hypothalamic projections to the ventral tegmental area. Neuroscience 111:379-387. CrossRef Medline

Fields RD, Eshete F, Stevens B, Itoh K (1997) Action potential-dependent regulation of gene expression: temporal specificity in $\mathrm{Ca} 2{ }^{+}$, cAMPresponsive element binding proteins, and mitogen-activated protein kinase signaling. J Neurosci 17:7252-7266. Medline

Georgescu D, Sears RM, Hommel JD, Barrot M, Bolaños CA, Marsh DJ, Bednarek MA, Bibb JA, Maratos-Flier E, Nestler EJ, DiLeone RJ (2005) The hypothalamic neuropeptide melanin-concentrating hormone acts in the nucleus accumbens to modulate feeding behavior and forced-swim performance. J Neurosci 25:2933-2940. CrossRef Medline

Giardino WJ, de Lecea L (2014) Hypocretin (orexin) neuromodulation of stress and reward pathways. Curr Opin Neurobiol 29:103-108. CrossRef Medline

Guo YP, Sun X, Li C, Wang NQ, Chan YS, He J (2007) Corticothalamic synchronization leads to $\mathrm{c}$-fos expression in the auditory thalamus. Proc Natl Acad Sci U S A 104:11802-11807. CrossRef Medline

Harris GC, Aston-Jones G (2006) Arousal and reward: a dichotomy in orexin function. Trends Neurosci 29:571-577. CrossRef Medline

Harris GC, Wimmer M, Aston-Jones G (2005) A role for lateral hypothalamic orexin neurons in reward seeking. Nature 437:556-559. CrossRef Medline

Hassani OK, Lee MG, Jones BE (2009) Melanin-concentrating hormone neurons discharge in a reciprocal manner to orexin neurons across the sleep-wake cycle. Proc Natl Acad Sci U S A 106:2418-2422. CrossRef Medline

Heffner HE, Heffner RS, Contos C, Ott T (1994) Audiogram of the hooded Norway rat. Hear Res 73:244-247. CrossRef Medline

Henny P, Jones BE (2006) Innervation of orexin/hypocretin neurons by GABAergic, glutamatergic or cholinergic basal forebrain terminals evidenced by immunostaining for presynaptic vesicular transporter and postsynaptic scaffolding proteins. J Comp Neurol 499:645-661. CrossRef Medline

Jones BE (2008) Modulation of cortical activation and behavioral arousal by cholinergic and orexinergic systems. Ann N Y Acad Sci 1129:26-34. CrossRef Medline

Jones BE, Muhlethaler M (2005) Modulation of cortical activity and sleepwake state by hypocretin/orexin. In: The hypocretins: integrators of physiological systems (de Lecea L, Sutcliffe JG, eds), pp 289-301. New York: Springer.

Lee MG, Manns ID, Alonso A, Jones BE (2004) Sleep-wake related discharge properties of basal forebrain neurons recorded with micropipettes in head-fixed rats. J Neurophysiol 92:1182-1198. CrossRef Medline

Lee MG, Hassani OK, Jones BE (2005) Discharge of identified orexin/hypocretin neurons across the sleep-waking cycle. J Neurosci 25:6716-6720. CrossRef Medline

Li A, Hindmarch CC, Nattie EE, Paton JF (2013) Antagonism of orexin receptors significantly lowers blood pressure in spontaneously hypertensive rats. J Physiol 591:4237-4248. CrossRef Medline

Luckman SM, Dyball RE, Leng G (1994) Induction of c-fos expression in hypothalamic magnocellular neurons requires synaptic activation and not simply increased spike activity. J Neurosci 14:4825-4830. Medline

Mahler SV, Moorman DE, Smith RJ, James MH, Aston-Jones G (2014) Motivational activation: a unifying hypothesis of orexin/hypocretin function. Nat Neurosci 17:1298-1303. CrossRef Medline

Maloney KJ, Cape EG, Gotman J, Jones BE (1997) High-frequency gamma electroencephalogram activity in association with sleep-wake states and spontaneous behaviors in the rat. Neuroscience 76:541-555. CrossRef Medline

Mileykovskiy BY, Kiyashchenko LI, Siegel JM (2005) Behavioral correlates of activity in identified hypocretin/orexin neurons. Neuron 46:787-798. CrossRef Medline

Mirenowicz J, Schultz W (1996) Preferential activation of midbrain dopamine neurons by appetitive rather than aversive stimuli. Nature 379:449451. CrossRef Medline

Nakamura K, Ono T, Tamura R (1987) Central sites involved in lateral hypothalamus conditioned neural responses to acoustic cues in the rat. J Neurophysiol 58:1123-1148. Medline

Nishino S, Mignot E (1997) Pharmacological aspects of human and canine narcolepsy. Prog Neurobiol 52:27-78. CrossRef Medline

Nishino S, Mignot E (2011) Narcolepsy and cataplexy. Handb Clin Neurol. 99:783-814. CrossRef Medline

Nishino S, Tafti M, Reid MS, Shelton J, Siegel JM, Dement WC, Mignot E (1995) Muscle atonia is triggered by cholinergic stimulation of the basal forebrain: implication for the pathophysiology of canine narcolepsy. J Neurosci 15:4806-4814. Medline

Olds J (1976) Brain stimulation and the motivation of behavior. Prog Brain Res 45:401-426. CrossRef Medline

Ono T, Sasaki K, Nakamura K, Norgren R (1985) Integrated lateral hypothalamic neural responses to natural and artificial rewards and cue signals in the rat. Brain Res 327:303-306. CrossRef Medline

Overeem S, van Nues SJ, van der Zande WL, Donjacour CE, van Mierlo P, Lammers GJ (2011) The clinical features of cataplexy: a questionnaire study in narcolepsy patients with and without hypocretin-1 deficiency. Sleep Med 12:12-18. CrossRef Medline

Peyron C, Faraco J, Rogers W, Ripley B, Overeem S, Charnay Y, Nevsimalova S, Aldrich M, Reynolds D, Albin R, Li R, Hungs M, Pedrazzoli M, Padigaru M, Kucherlapati M, Fan J, Maki R, Lammers GJ, Bouras C, Kucherlapati R, et al. (2000) A mutation in a case of early onset narcolepsy and a generalized absence of hypocretin peptides in human narcoleptic brains. Nat Med 6:991-997. CrossRef Medline

Pinault D (1996) A novel single-cell staining procedure performed in vivo under electrophysiological control: morpho-functional features of juxtacellularly labeled thalamic cells and other central neurons with biocytin or neurobiotin. J Neurosci Methods 65:113-136. CrossRef Medline

Reid MS, Tafti M, Geary JN, Nishino S, Siegel JM, Dement WC, Mignot E (1994) Cholinergic mechanisms in canine narcolepsy-I. Modulation of cataplexy via local drug administration into the pontine reticular formation. Neuroscience 59:511-522. CrossRef Medline

Rolls ET, Burton MJ, Mora F (1980) Neurophysiological analysis of brainstimulation reward in the monkey. Brain Res 194:339-357. CrossRef Medline

Schultz W (2007) Behavioral dopamine signals. Trends Neurosci 30: 203-210. CrossRef Medline

Soulière F, Urbain N, Gervasoni D, Schmitt P, Guillemort C, Fort P, Renaud B, Luppi PH, Chouvet G (2000) Single-unit and polygraphic recordings associated with systemic or local pharmacology: a multi-purpose stereotaxic approach for the awake, anaesthetic-free, and head-restrained rat. J Neurosci Res 61:88-100. CrossRef Medline

Thannickal TC, Moore RY, Nienhuis R, Ramanathan L, Gulyani S, Aldrich M, Cornford M, Siegel JM (2000) Reduced number of hypocretin neurons in human narcolepsy. Neuron 27:469-474. CrossRef Medline

Tsujino N, Sakurai T (2009) Orexin/hypocretin: a neuropeptide at the interface of sleep, energy homeostasis, and reward system. Pharmacol Rev 61:162-176. CrossRef Medline

Winsky-Sommerer R, Yamanaka A, Diano S, Borok E, Roberts AJ, Sakurai T, Kilduff TS, Horvath TL, de Lecea L (2004) Interaction between the corticotropin-releasing factor system and hypocretins (orexins): a novel circuit mediating stress response. J Neurosci 24:11439-11448. CrossRef Medline

Yoshida K, McCormack S, España RA, Crocker A, Scammell TE (2006) Afferents to the orexin neurons of the rat brain. J Comp Neurol 494: 845-861. CrossRef Medline 